$$
\text { DOE/PC/79930- - } 13
$$

\title{
PYROLYSIS AND GASIFICATION OF COAL AT HIGH TEMPERATURES
}

DOE/PC/79930--TI3

Grant Number DE-FG22-87PC79930

DE92 013613

QUARTERLY PROGRESS REPORT

(Quarter \#8: 6/15/1989 to 9/15/89)

PRINCIPAL INVESTIGATOR: Prof. Kyriacos Zygourakis

Department of Chemical Engineering

Rice University

Houston, Texas 77251-1892

Tel. (713) 527-8101 Ext. 3509.

PROJECT MANAGER:

Dr. James R. Longanbach

Morgantown Energy Technology Center

PO Box 880

Collins Ferry Road

Morgantown, West Virginia 26505

GRANT PERIOD:

$9 / 15 / 1987$ to $9 / 14 / 1990$

MASTER

DISTRIBUTION OF THIS DOCUMENT IS UNLIMITED

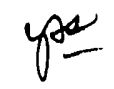

US/DOE Patent Clearance is not required

prior to the publication of this document

\author{
DISCLAIMER
}

\begin{abstract}
This report was prepared as an account of work sponsored by an agency of the United States Government. Neither the United States Government nor any agency thereof, nor any of their employees, makes any warranty, express or implied, or assumes any legal liability or responsibility for the accuracy, completeness, or usefulness of any information, apparatus, product, or process disclosed, or represents that its use would not infringe privately owned rights. Reference herein to any specific commercial product, process, or service by trade name, trademark, manufacturer, or otherwise does not necessarily constitute or imply its endorsement, recom-

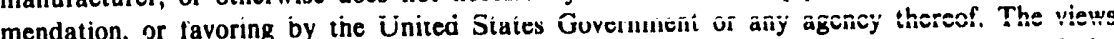
and opinions of authors expressed herein do not necessarily state or reflect those of the United States Government or any agency thereof.
\end{abstract}




\section{SHORT DESCRIPTION OF TASKS}

\section{(A) Effects of Pyrolysis Conditions on Macropore Structure}

Coals of different ranks will be pyrolyzed in a microscope hot-stage reactor using inert and reacting atmospheres. The macropore structure of the produced chars will be characterized using video microscopy and digital image processing techniques to obtain pore size distributions. Comparative studies will quantify the effect of pyrolysis conditions (heating rates, final heat treatment temperatures, particle size and inert or reacting atmosphere) on the pore structure of the devolatilized chars.

\section{(B) Gasification Under Strong Intraparticle Diffusional Limitations}

The devolatilized chars will be gasified in the regime of strong intraparticle diffusional limitations using $\mathrm{O}_{2} / \mathrm{N}_{2}$ and $\mathrm{O}_{2} / \mathrm{H}_{2} \mathrm{O}_{2} \mathrm{~N}_{2}$ mixtures. Constant temperature and programmedtemperature experiments in a TGA will be used for these studies. Additional gasification experiments performed in the hot-stage reactor will be videotaped and selected images will be analyzed to obtain quantitative data on particle shrinkage and fragmentation.

\section{(C) Mathematical Modeling and Model Validation}

Discrete mathematical models will be developed and validated using the experimental gasification data. Structural properties of the unreacted chars will be used to generate computational grids simulating the pore structure of the solid. Simulations will then provide the evolution of observed reaction rates with conversion. The size distribution of particle fragments obtained as the reaction front moves through the particle will also be obtained. Proper statistical averaging of the results from these simulations will yield the expected behavior for each char. Comparisons of experimental data and theoretical predictions will icientify the fundamental phenomena that must be included in a mathematical description of the process, thus leading to the development of accurate models for the gasification of coal particles. 


\section{SUMMARY}

We have initiated a new series of pyrolysis and gasification experiments that will consider three premium coals from the Argonne collection. This study will investigate the effect of the following parameters on the macropore structure and reactivity of the produced chars: (a) pyrolysis heating rate; (b) final heat treatment temperature (or HTT); (c) duration of heat treatment at HTT; (d) pyrolysis atmosphere (inert or reactive) and (e) coal rank. Pyrolysis experiments will be carried out in the thermogravimetric apparatus at heating rates between 0.1 and $25 \mathrm{C} / \mathrm{s}$. The thermogravimetric reactor offers significant advantages for pyrolysis studies since we can (i) continuously monitor the devolatilization rate and (ii) easily and accurately compute the total volatile yield. A parallel set of pyrolysis experiments will be conducted on the microscope hot-stage reactor and a large part of our research effort during the past quarter was devoted to this reactor. The video microscopy system was put together, a new controller was built for the heating element of the reactor and the microreactor was interfaced with the mass flow controllers we use for our thermogravimetric system.

Finally, we have considerably improved our image processing method for calculating the structural parameters of devolatilized chars. A new procedure was developed to rapidly smooth the original $640 \times 480$ binary images used for structural measurements. The new method requires very short computational times and could develop into a routine analytical technique for structural measurements.

\section{TASK A: Effects of Pyrolysis Conditions on Macropore Structure}

In the two previous quarterly reports we described the development of a new procedure for smoothing the pore (and particle) boundaries in order to improve the macropore surface area estimates. According to that procedure, each $640 \times 480$ image is converted to an artificial B\&W image with only two grey levels (black and white). A filter with a $3 \times 3$ kernel is then applied to the B\&W image resulting in a "blurring" of the sharp boundaries. The filtered image is then segmented and magnified by a factor of 4 to obtain a binary image with smooth pore (and particle) boundaries. This procedure also filters out small pores that consist of one or two pixels. Such small pores may be artifacts due to noise in the original video signal or in the digitizer. This smoothing procedure was applied to estimate the structural properties of five Illinois \#6 chars produced at different pyrolysis heating rates $\left(0.1\right.$ to $\left.1000^{\circ} \mathrm{C} / \mathrm{s}\right)$. 
This procedure (hereafter referred to as procedure $\mathbf{A}$ ) is extremely CPU-intensive since it creates and analyzes binary images with $2560 \times 1920$ pixels (i.e. 16 times larger than the original binary images). In order to speed up the computation of the structural parameters, we developed and evaluated a new procedure that works on the original $640 \times 480$ images. An isotropic dilation operation is first applied on the raw images. This operation "enlarges" the solid part of the binary image and, consequently, shrinks the pores in an isotropic fashion (i.e. the pores shrink by the same amount in all directions). The dilation is followed by an erosion operation. This sequence of two operations will be referred to as smoothing procedure B. While it essentially preserves the size and shape of most pores, this procedure smooths the pore boundaries and eliminates most of the small pores (consisting of one or two pixels) that may be due to video noise. Figures $1 \mathrm{~A}$ and $1 \mathrm{~B}$ give an example of two representative cross-sections before and after the smoothing operation. These figures should be contrasted with Figures $1 \mathrm{~A}$ and $1 \mathrm{~B}$ in the fifth quarterly report for this contract.

Tables 1, 2 and 3 give all the macropore structural properties of the five Illinois \#6 chars computed (1) from the raw images, (2) after smoothing the raw images according to procedure $\mathrm{A}$ (2560x 1920 pixel binary images) and (3) after smoothing the raw images according to procedure $B$ (640×480 pixel binary images). Figure 2 also presents the surface area densities and specific macropore surface areas computed from all three procedures.Clearly, the two smoothing procedures give virtually indistinguishable results.Smoothing according to procedure $\mathrm{B}$, however, requires only a small fraction of the CPU time required to compute the properties according to procedure A.

Figures $3 \mathrm{~A}$ and $3 \mathrm{~B}$ present cross-plots of the evolution of the average macroporosity $\mathrm{e}$, the specific macropore surface area $S_{\mathrm{g}}\left(\mathrm{m}^{2} / \mathrm{cm}^{3}\right.$ solid) and the average area-equivalent particle radius $\mathbf{R}_{\text {avg }}$ computed from 48 particle sections computed as

$$
R_{\text {avg }}=\left(\frac{\sum_{i=1}^{N} A_{i}}{N \pi}\right)^{\frac{1}{2}}
$$

where $A_{i}$ is the area of the $\mathrm{i}$-th particle cross-section and $\mathrm{N}$ is the total number of cross-sections. The plots clearly show that these three quantities are strongly correlated.

Figures $4 \mathrm{~A}$ and $4 \mathrm{~B}$ plot the average porosities and specific surface areas $\mathrm{S}_{\mathrm{g}}$ of the five Illinois \#6 char samples vs. the average particle radius. The porosity vs. radius plot shows the large 
increase in the amount of released volatiles when the pyrolysis heating rate increases from 0.1 to 1 ${ }^{\circ} \mathrm{C} / \mathrm{s}$. Note that the average particle radii computed for these two samples are almost identical. For still higher heating rates, the macroporosity appears to vary linearly with particle radius indicating that the amount of volatiles released during pyrolysis continues to be influenced significantly by the heating rate. Figure 4B indicates that the specific surface area $S_{\mathrm{g}}$ is also highly correlated with the average particle radius. Taus, a closer analysis of the structural measurement data appears to indicate that particle swelling may be a good indicator of the total specific macropore surface area, at least for this char and pyrolysis procedure.

Thermogravimetric Reactor: We have already started a new series of pyrolysis and gasification experiments. These studies will consider three premium coals from the Argonne collection: Illinois \#6, Pittsburgh \#8 and Utah. The first set of pyrolysis experiments are carried out in the thermogravimetric apparatus at heating rates between 0.1 and $10 \mathrm{C} / \mathrm{s}$ (a maximum heating rate of $20-25 \mathrm{C} / \mathrm{s}$ is achievable in this reactor). The significant advantage of this method is that it can provide instantaneous devolatilization rates and total volatile yields for any chosen temperature program. Figure 5 shows the devolatilization rates from a preliminary run with a Texas lignite. As the heating rate increases, the peak in the devolatilization rate broadens and is shifted towards higher temperatures. The total volatile yields for these runs is also a function of the heating rate. Figure 6 plots the devolatilization rate vs. conversion for these runs.

Gasification runs can start on the TGA as soon as the pyrolysis run is completed. This is a added advantage of our method since we avoid unnecessary handling and prolonged storage of the pyrolyzed chars. Our preliminary runs have revealed significant differences in the reactivity of chars pyrolyzed under different heating rates in nitrogen. One of the measures of reactivity we employ is the evolution of the specific reaction rate $R_{m}$ with conversion. The rate $R_{m}$ is defined as

$$
R_{m}=\frac{1}{m(t)} \frac{d m}{d t}
$$

where $m(t)$ is the remaining mass of carbon at time $t$. Figure 7 shows the reactivity patterns from the gasification with air at $450{ }^{\circ} \mathrm{C}$ of three chars produced at $0.1,1$ and $10^{\circ} \mathrm{C} / \mathrm{s}$ in nitrogen. The results seem to indicate significant differences in the intrinsic reactivity of these chars. At $50 \%$ conversion, the char produced at $10^{\circ} \mathrm{C} / \mathrm{s}$ is 5 times as reactive as the char produced at $0.1{ }^{\circ} \mathrm{C} / \mathrm{s}$. These are, of course, preliminary results and no conclusions can be drawn from them, even for the specific coal used here. Figures 5, 6 and 7, however, demonstrate the capabilities of our thermogravimetric apparatus. 
The pyrolysis studies under way will investigate the effect of the following parameters on the macropore structure and reactivity of the produced chars.
(a) pyrolysis heating rate;
(b) final heat treatment temperature (or HTT);
(c) duration of heat treatment at HTT;
(d) pyrolysis atmosphere (inert or reactive) and
(e) coal rank.

Microscope Hot-stage Reactor: A large part of our research effort during the past quarter was devoted to the microscope hot-stage reactor. A monocular zoom microscope was acquired and equipped with a fiber-optic light source and a video camera. The original microreactor was re-built to minimize dead time and improve the deteriorated electrical connections. A new controller was built for the heating element and the microreactor was interfaced with the mass flow controllers we use for out thermogravimetric system. Figure 8 shows a schematic of the video microscopy system and Figure 9 shows a digitized image of the hot-stage reactor, the optical microscope an the video camera. 
TABLE 1

Structural Properties for Illinois \#6 chars

Computed from Raw 640x480 Images

\begin{tabular}{rcccc} 
HEATING & MAXIMUM & PARTICLE RADIUS & \multicolumn{2}{c}{ MACROPOROSITY } \\
RATE & PORE RADIUS & Maximum Average & Lower Average Upper \\
$(\mathrm{C} / \mathrm{s})$ & $(\mu \mathrm{m})$ & $(\mu \mathrm{m})$ & & \\
\end{tabular}

$\begin{array}{rrrrrrr}0.1 & 133.6 & 176.3 & 132.7 & 0.274 & 0.333 & 0.382 \\ 1.0 & 172.9 & 191.1 & 132.5 & 0.496 & 0.549 & 0.601 \\ 10.0 & 152.6 & 221.2 & 153.4 & 0.681 & 0.722 & 0.774 \\ 100.0 & 173.5 & 215.2 & 161.1 & 0.734 & 0.769 & 0.791 \\ 1000.0 & 187.9 & 244.7 & 169.6 & 0.815 & 0.842 & 0.861\end{array}$

HEATING

RATE

$(\mathrm{C} / \mathrm{s})$
SURFACE AREA DENSITY

Lower Average Upper $\left(\mathrm{m}^{2} / \mathrm{cm}^{3}\right.$ particle )
SPECIFIC SURFACE AREA

Lower Average Upper $\left(\mathrm{m}^{2} / \mathrm{cm}^{3}\right.$ solid )

$\begin{array}{rrrrccc}0.1 & 321.6 & 503.3 & 604.9 & 443.5 & 754.7 & 918.9 \\ 1.0 & 664.3 & 735.6 & 922.6 & 1426.7 & 1630.1 & 2193.4 \\ 0.0 & 843.3 & 888.0 & 942.3 & 2702.5 & 3189.4 & 3877.8 \\ 100.0 & 601.0 & 696.3 & 803.7 & 2876.9 & 3013.9 & 3168.0 \\ 1000.0 & 651.8 & 725.4 & 773.5 & 4424.7 & 4593.7 & 4687.7\end{array}$


TABLE 2

Structural Properties for Illinois \#6 chars

Computed from Smoothed 2560x1920 Images

Smoothing Procedure: A

\begin{tabular}{|c|c|c|c|c|c|c|}
\hline \multirow{2}{*}{$\begin{array}{r}\text { HEATING } \\
\text { RATE } \\
(\mathrm{C} / \mathrm{s})\end{array}$} & \multirow{2}{*}{$\begin{array}{c}\text { MAXIMUM } \\
\text { PORE RADIUS } \\
(\mu \mathrm{m})\end{array}$} & \multicolumn{2}{|c|}{ PARTICLE RADIUS } & \multicolumn{3}{|c|}{ MACROPOROSITY } \\
\hline & & $\begin{array}{r}\text { Maximum } \\
(\mu\end{array}$ & $\begin{array}{l}\text { Average } \\
\text { n) }\end{array}$ & Lower & Average & Upper \\
\hline 0.1 & 133.6 & 176.2 & 132.3 & 0.272 & 0.327 & 0.380 \\
\hline 1.0 & 172.9 & 191.1 & 131.6 & 0.493 & 0.541 & 0.599 \\
\hline 10.0 & 152.7 & 213.4 & 151.7 & 0.678 & 0.713 & 0.756 \\
\hline 100.0 & 173.5 & 215.1 & 157.8 & 0.731 & 0.757 & 0.787 \\
\hline 1000.0 & 188.1 & 244.7 & 166.9 & 0.806 & 0.834 & 0.859 \\
\hline
\end{tabular}

\begin{tabular}{|c|c|c|c|c|c|c|}
\hline \multirow{3}{*}{$\begin{array}{r}\text { HEATING } \\
\text { RATE } \\
(\mathrm{C} / \mathrm{s})\end{array}$} & \multicolumn{3}{|c|}{ SURFACE AREA DENSITY } & \multicolumn{3}{|c|}{ SPECIFIC SURFACE AREA } \\
\hline & Lower & Average & Upper & Lower & Average & Upper \\
\hline & \multicolumn{3}{|c|}{$\left(\mathrm{m}^{2} / \mathrm{cm}^{3}\right.$ particle $)$} & \multicolumn{3}{|c|}{$\left(\mathrm{m}^{2} / \mathrm{cm}^{3}\right.$ solid $)$} \\
\hline 0.1 & 290.5 & 440.4 & 521.2 & 399.8 & 654.2 & 787.2 \\
\hline 1.0 & 590.1 & 662.4 & 842.0 & 1221.6 & 1442.1 & 1981.8 \\
\hline 10.0 & 800.7 & 811.1 & 865.3 & 2496.2 & 2828.6 & 3278.3 \\
\hline 100.0 & 555.9 & 651.7 & 729.0 & 2519.0 & 2686.1 & 2830.3 \\
\hline 1000.0 & 577.7 & 652.7 & 735.5 & 3799.0 & 3938.4 & 4086.0 \\
\hline
\end{tabular}


TABLE 3

Structural Properties for Illinois \#6 chars

Computed from Smoothed 640x480 Images

Smoothing Procedure: B

(Dilation/Erosion)

\begin{tabular}{|c|c|c|c|c|c|c|}
\hline \multirow{3}{*}{$\begin{array}{r}\text { HEATING } \\
\text { RATE } \\
(\mathrm{C} / \mathrm{s})\end{array}$} & \multirow{3}{*}{$\begin{array}{c}\text { MAXIMUM } \\
\text { PORE RADIUS } \\
(\mu \mathrm{m})\end{array}$} & \multicolumn{2}{|c|}{ PARTICLE RADIUS } & \multicolumn{3}{|c|}{ MACROPOROSITY } \\
\hline & & MAX & AVG & Lower & Ayerage & Upper \\
\hline & & \multicolumn{2}{|c|}{$(\mu \mathrm{m})$} & & & \\
\hline 0.1 & 133.6 & 176.3 & 132.7 & 0.270 & 0.329 & 0.378 \\
\hline 1.0 & 172.8 & 191.1 & 132.5 & 0.490 & 0.543 & 0.596 \\
\hline 10.0 & 152.6 & 221.1 & 153.4 & 0.675 & 0.716 & 0.770 \\
\hline 100.0 & 173.4 & 215.1 & 157.8 & 0.729 & 0.765 & 0.788 \\
\hline 1000.0 & 187.8 & 244.7 & 169.6 & 0.809 & 0.836 & 0.856 \\
\hline HEATING & \multicolumn{3}{|c|}{ SURFACE AREA DENSITY } & \multicolumn{3}{|c|}{ SPECIFIC SURFACE AREA } \\
\hline RATE & Lower & Average & Upper & Lower & Average & Upper \\
\hline$(\mathrm{C} / \mathrm{s})$ & \multicolumn{3}{|c|}{$\left(\mathrm{m}^{2} / \mathrm{cm}^{3}\right.$ particle $)$} & \multicolumn{3}{|c|}{$\left(\mathrm{m}^{2} / \mathrm{cm}^{3}\right.$ solid $)$} \\
\hline 0.1 & 290.3 & 441.5 & 512.2 & 399.0 & 657.6 & 770.1 \\
\hline 1.0 & 596.8 & 665.7 & 853.6 & 1272.5 & 1457.4 & 2001.6 \\
\hline 10.0 & 786.0 & 826.3 & 875.8 & 2500.5 & 2913.7 & $35-1$ \\
\hline 100.0 & 566.2 & 649.5 & 739.8 & 2633.3 & 2762.7 & 2914.4 \\
\hline 1000.0 & 584.2 & 647.4 & 729.3 & 3809.7 & 3947.1 & 4043.8 \\
\hline
\end{tabular}



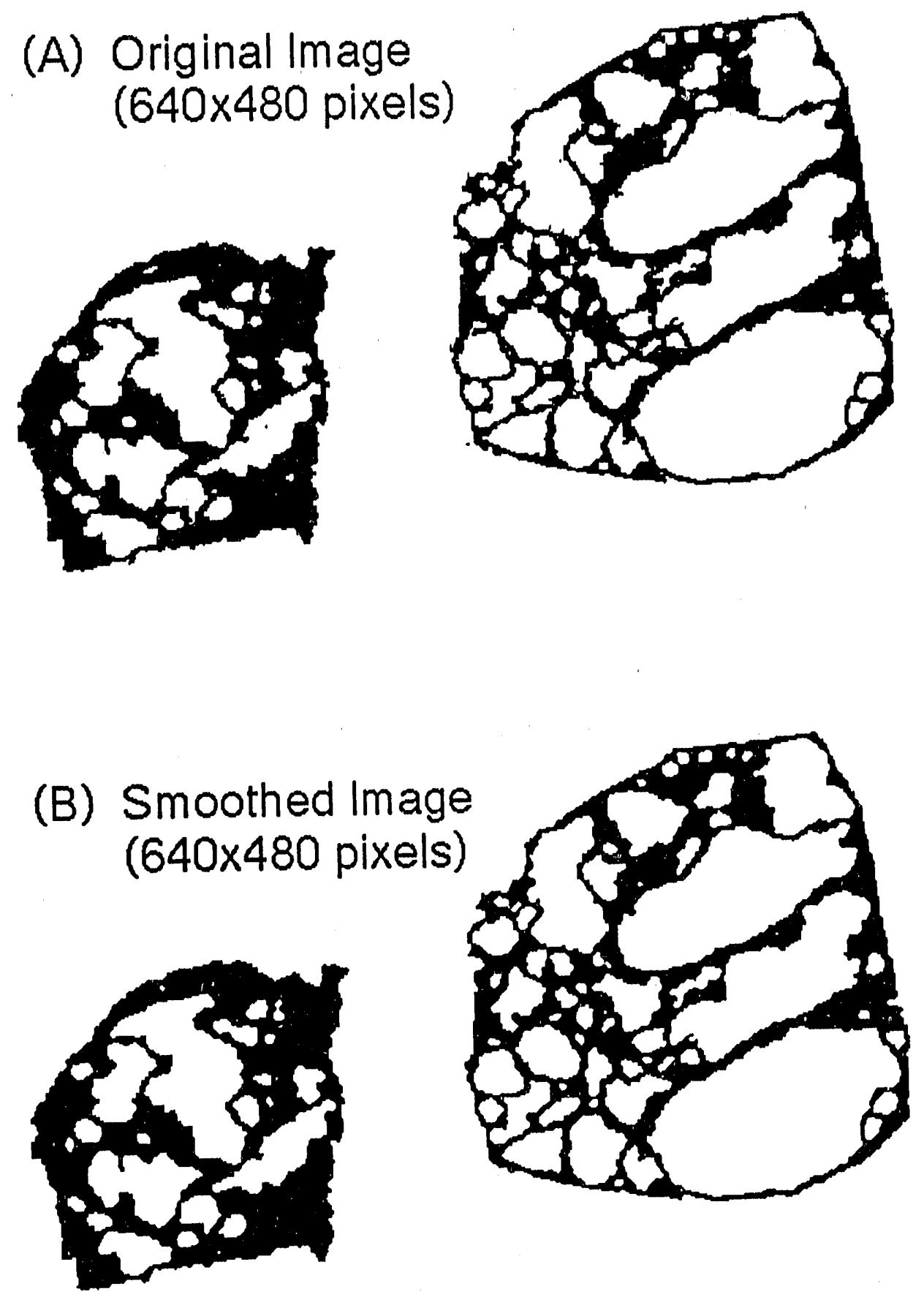

Figure 1: Original (A) and smoothed (B) images for two char particle cross-sections 

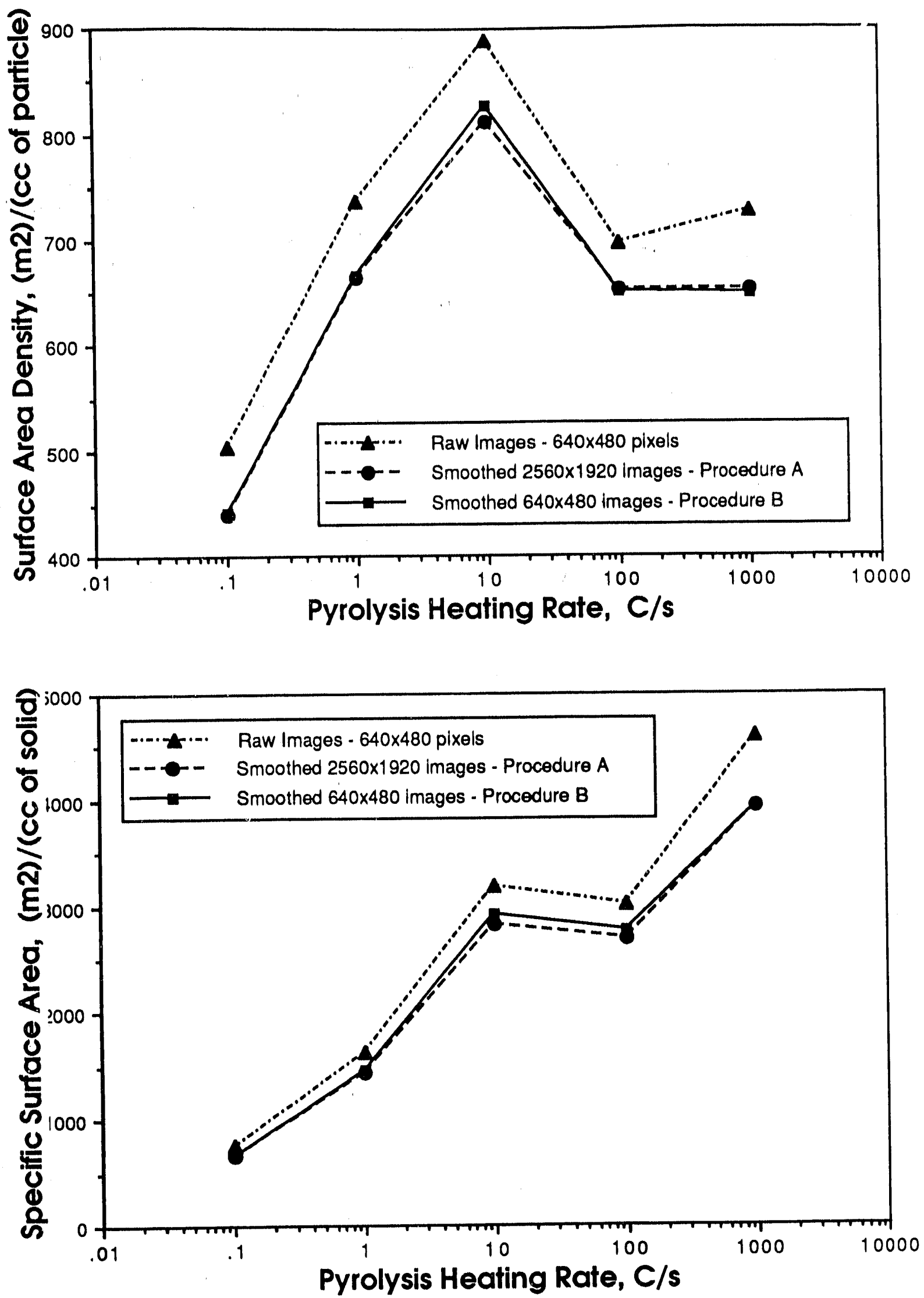

Figure 2: $\quad$ Effect of pyrolysis heating rate on the macropore surface area density (A) and specific macropore surface area (bottom) for five Illinols \#6 chars. Comparison of three measurement techniques. 

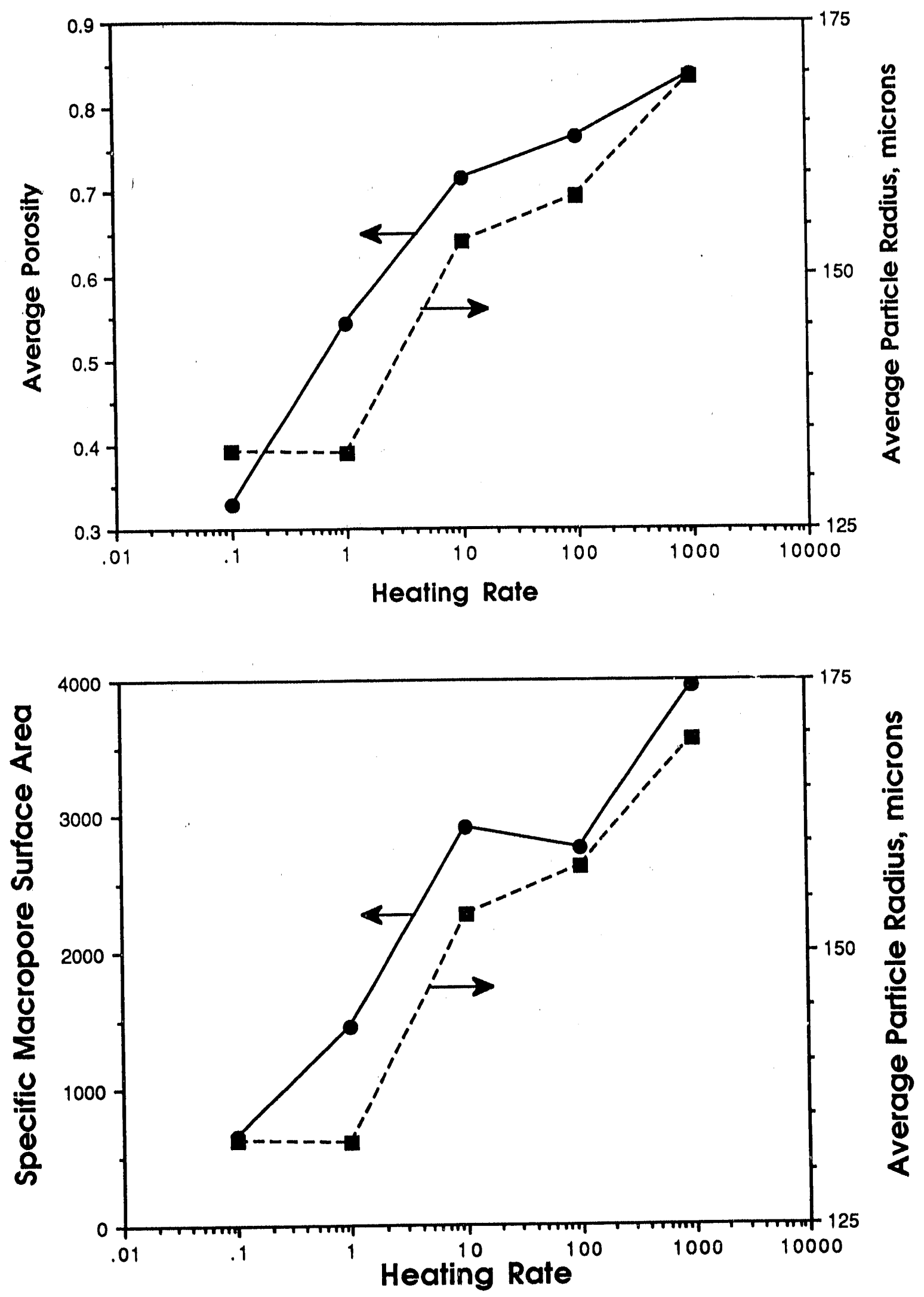

Figure 3: Plots showing the effect of pyrolysis heating rate on the average porosity. average particle radius and specific macropore surface area. 

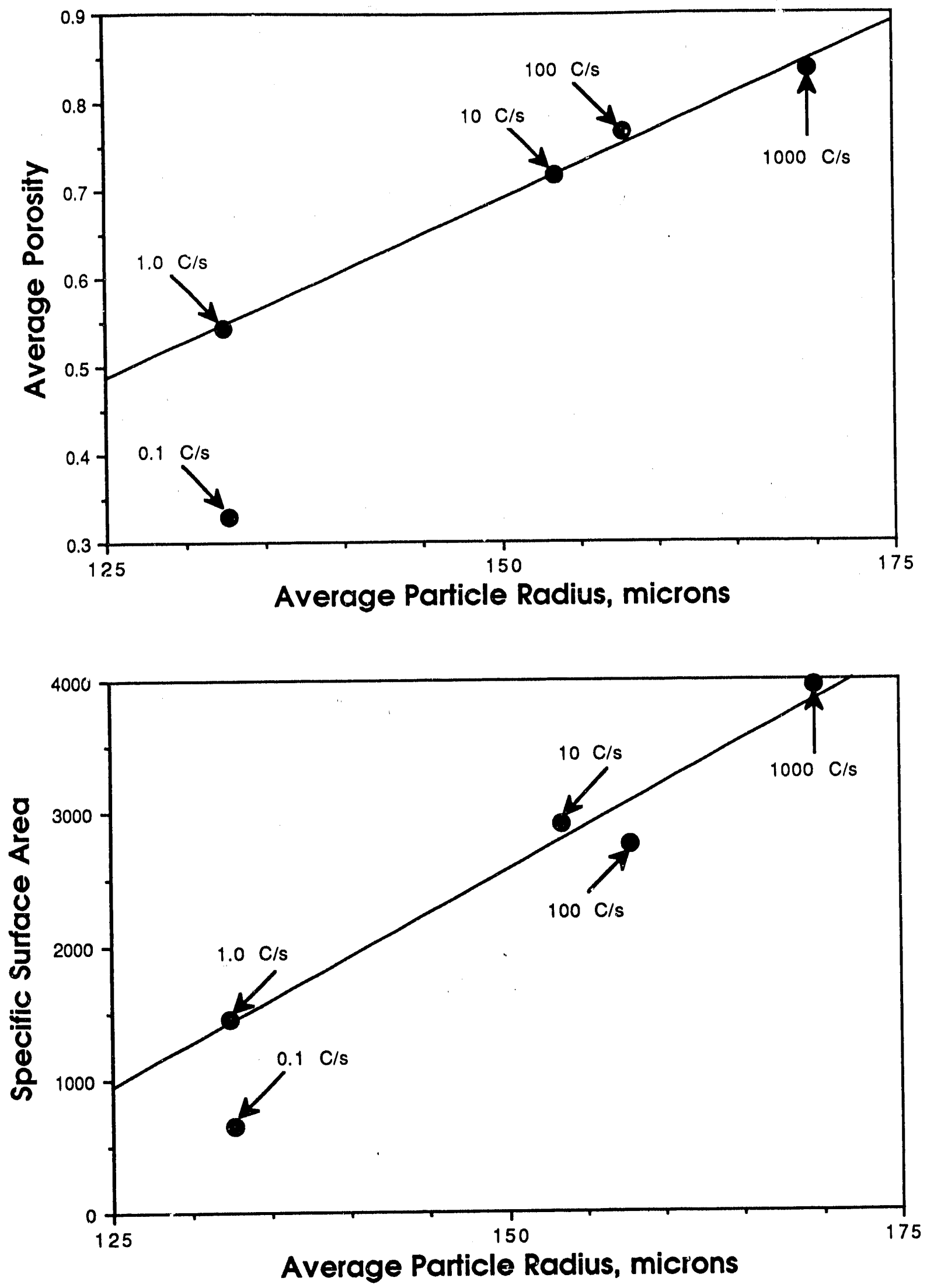

Figure 4: The dependence of average porosity and specific macropore surface area on particle size. 


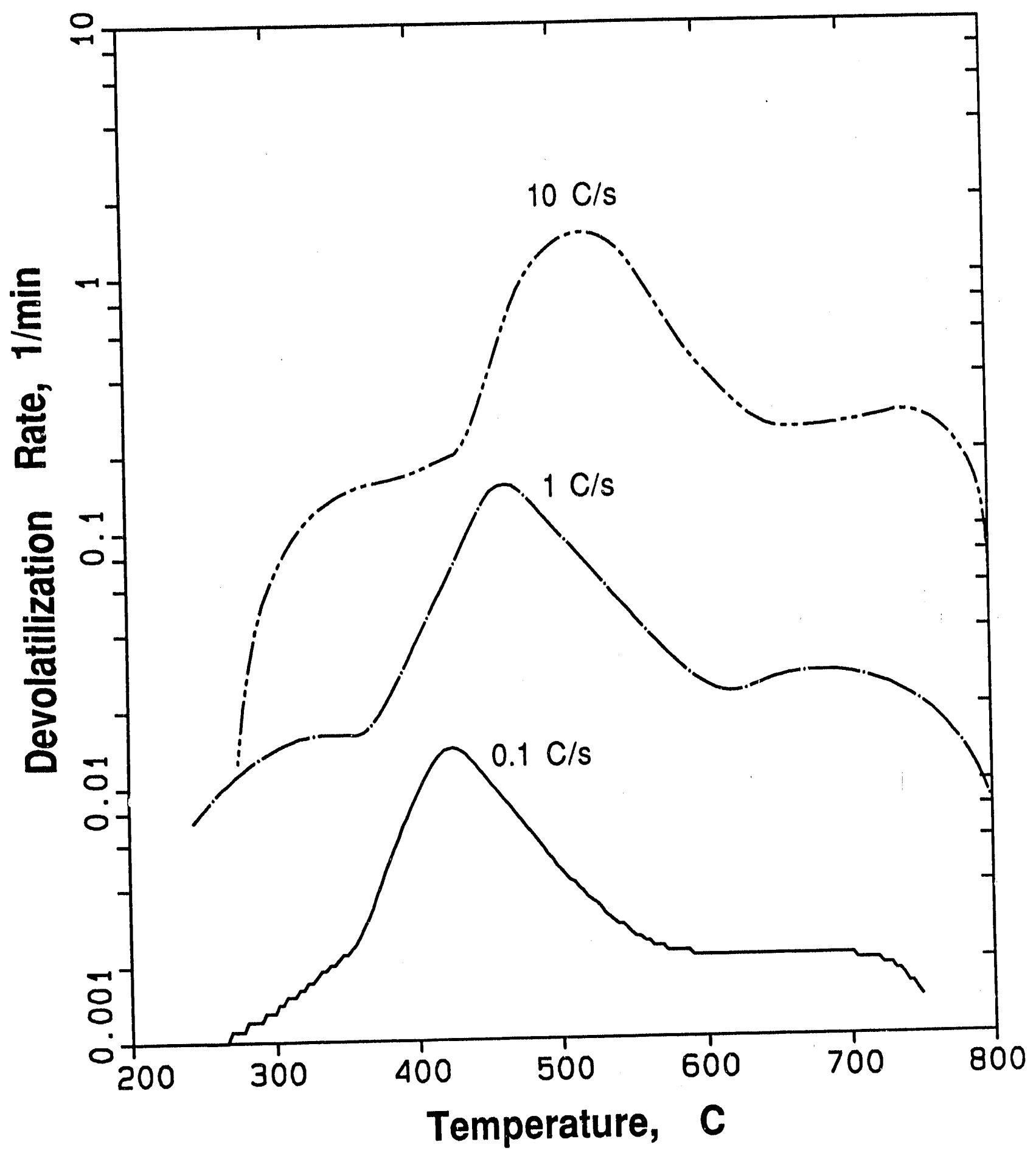

Figure 5: The evolution of devolatilization rates of a lignite coal pyrolyzed at three different heating rates in a thermogravimetric reactor. 


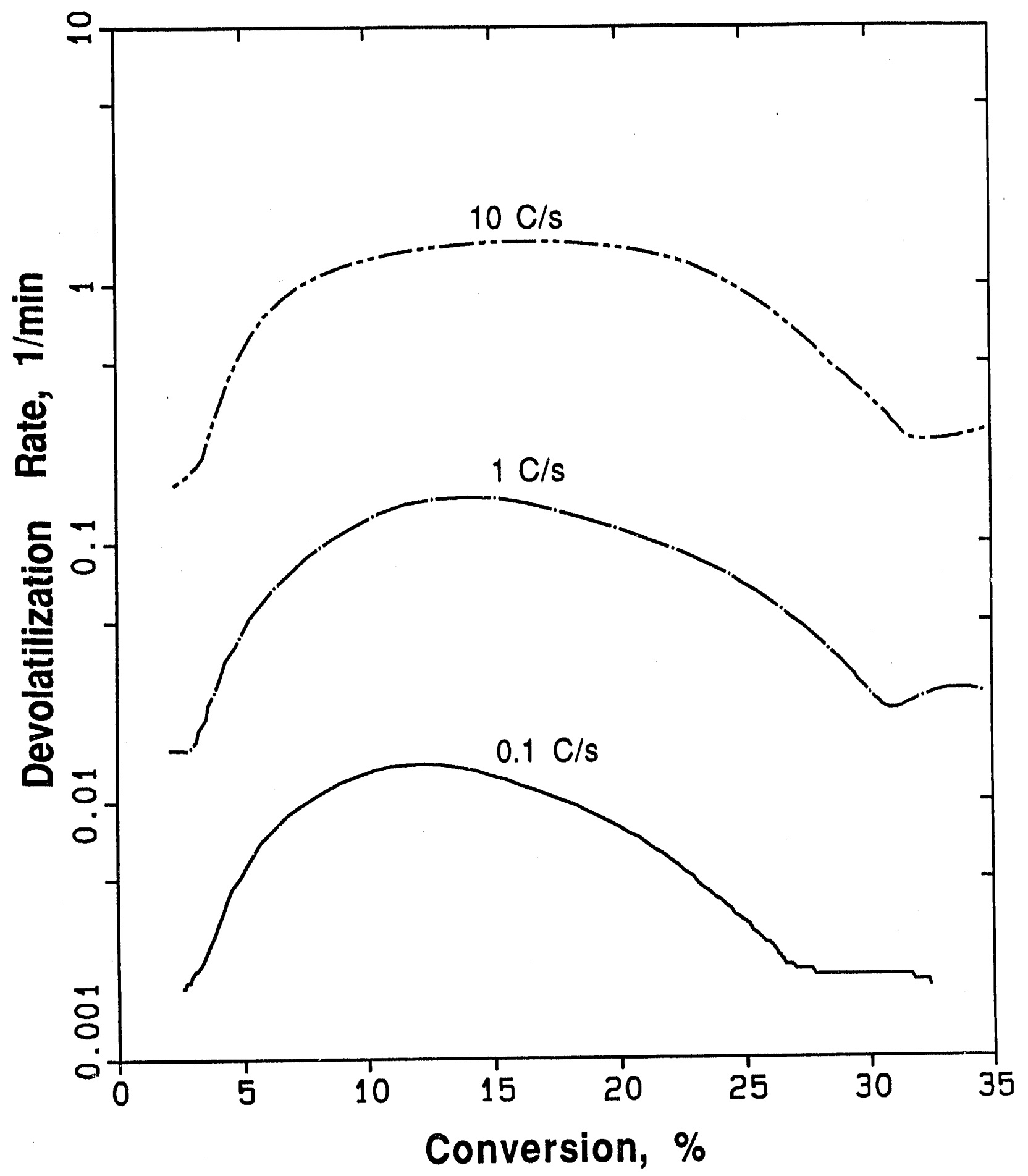

Figure 6: Devolatilization rate vs. conversion pattern for a lignite coal pyrolyzed at three different heating rates in a thermogravimetric reactor. 


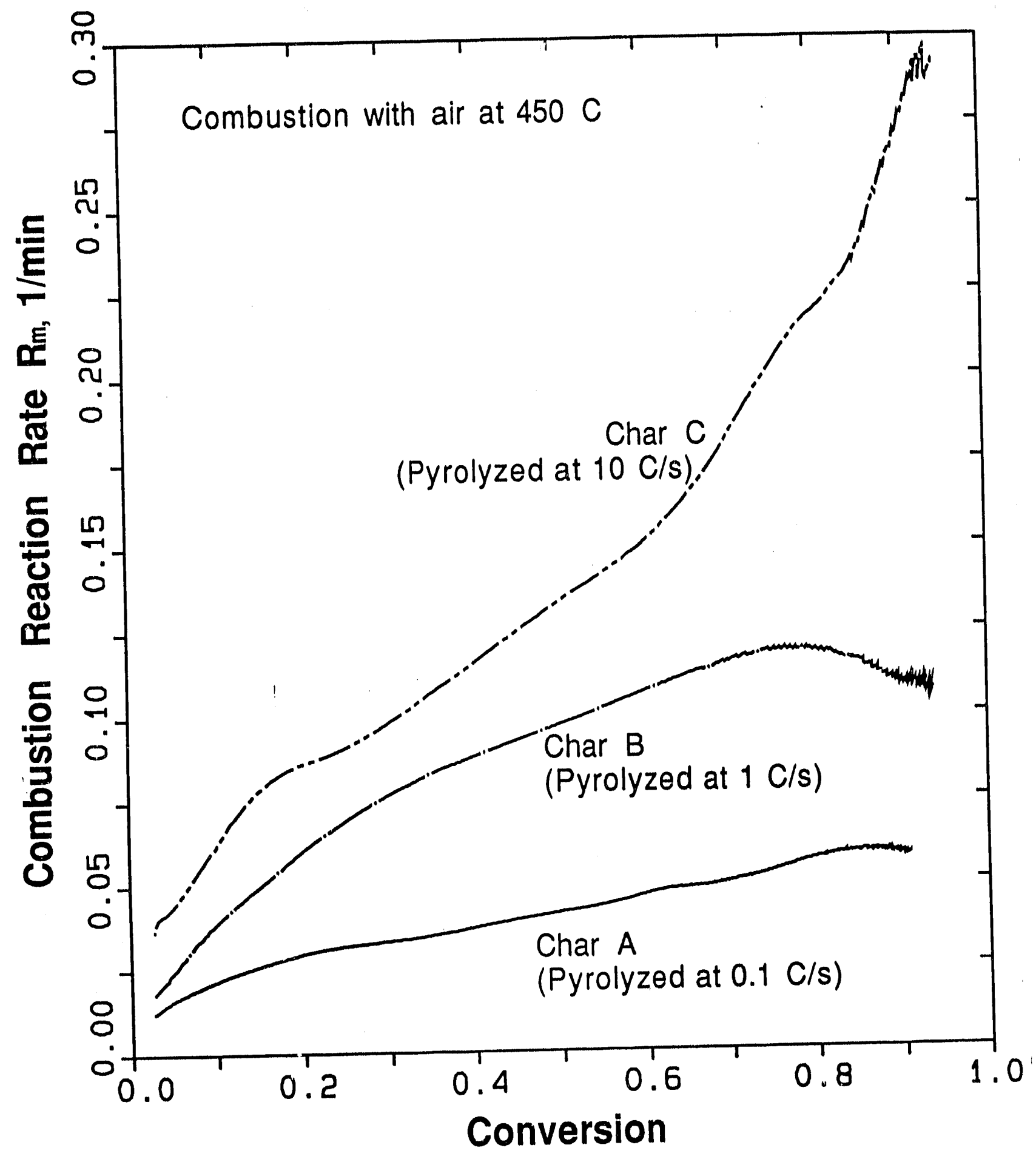

Figure 7: Gasification rate vs. conversion patterns for three lignite chars produced at different pyrolysis heating rates. The three chars were gasified with $\mathrm{O}_{2}$ at $450 \mathrm{C}$. 


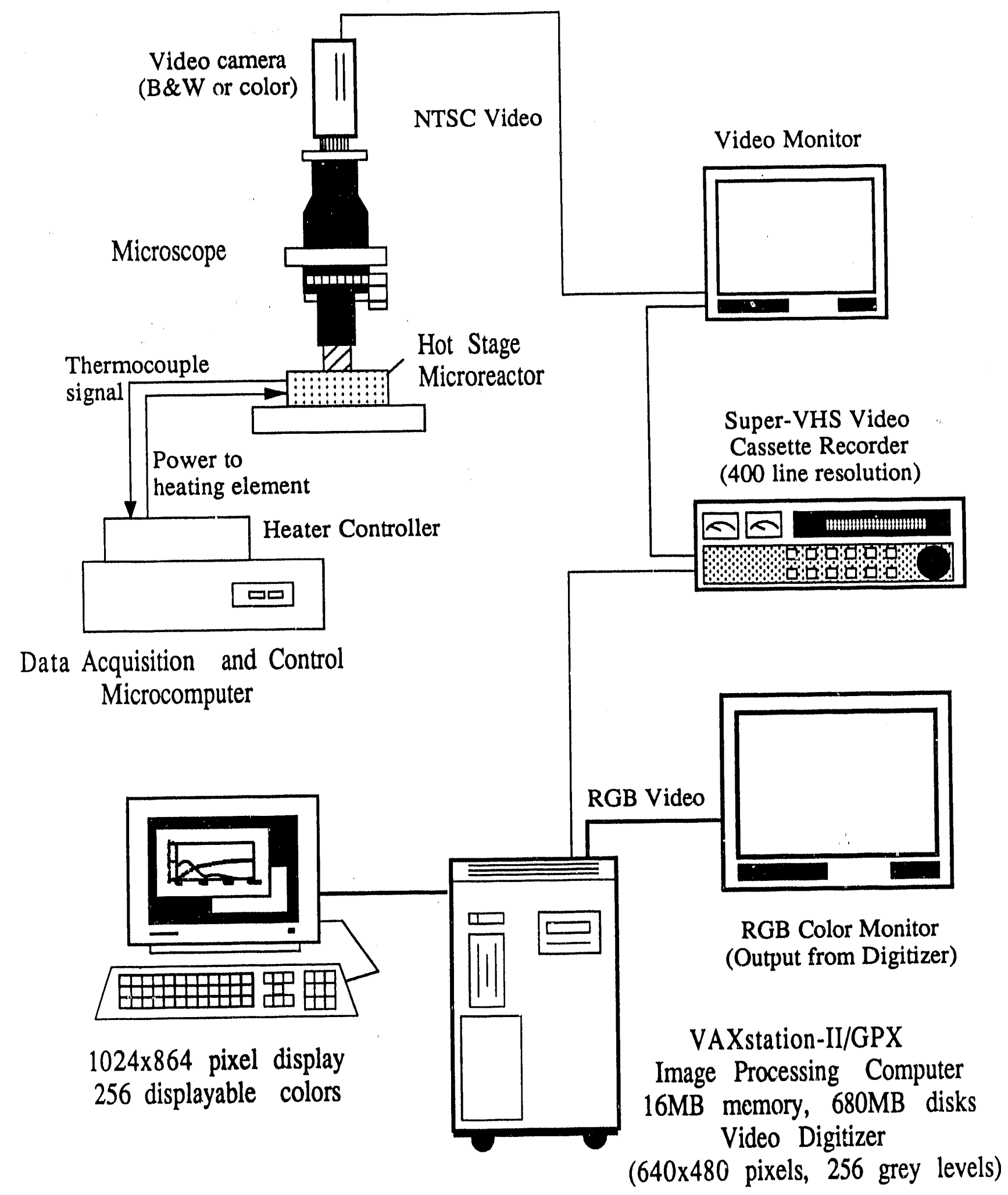

Figure 8: Schematic showing the video microscopy system for the hot-stage reactor. 


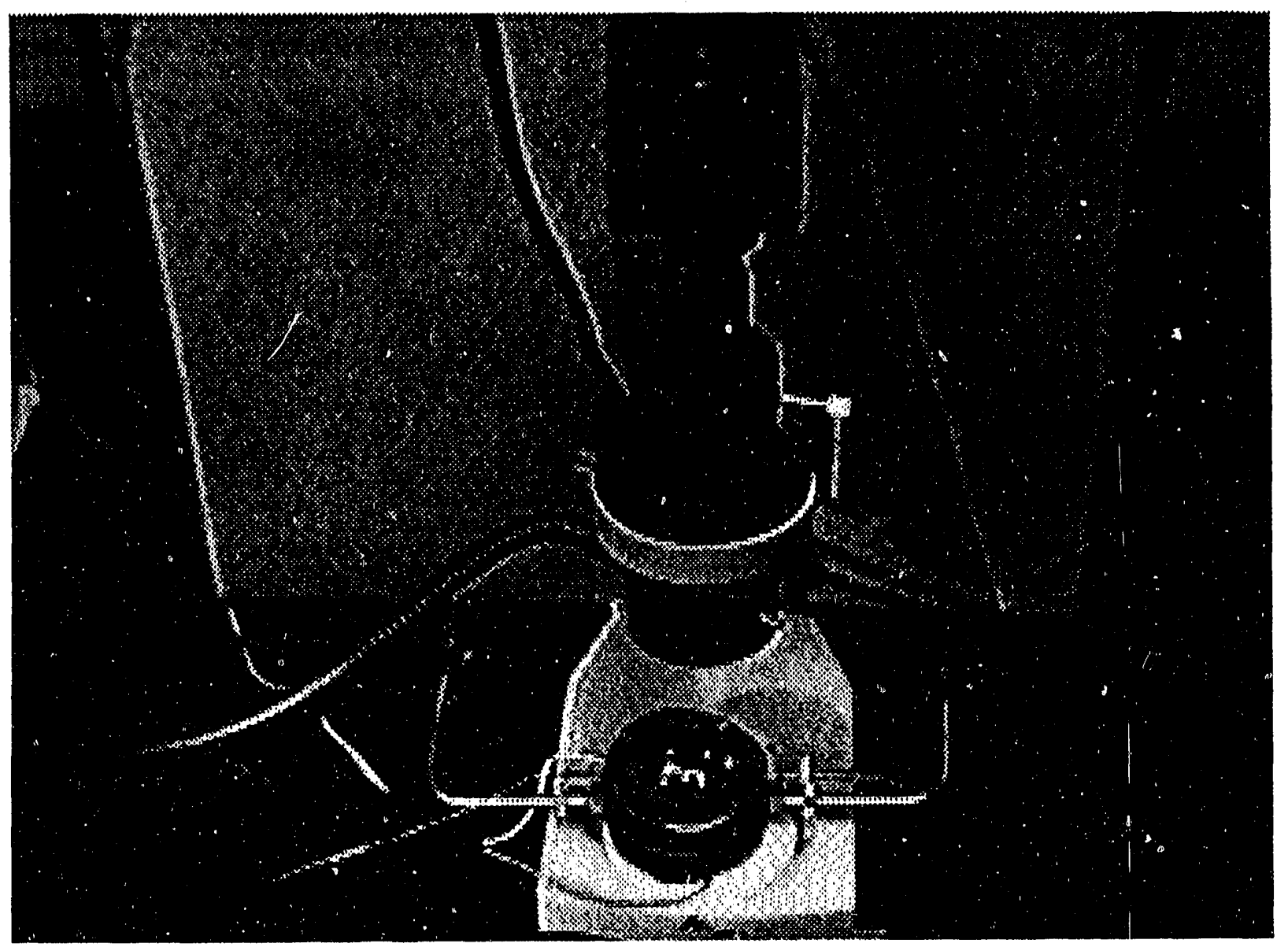

Figure 9: Digitized image showing the hot-stage reactor, the optical microscope and the video camera. 

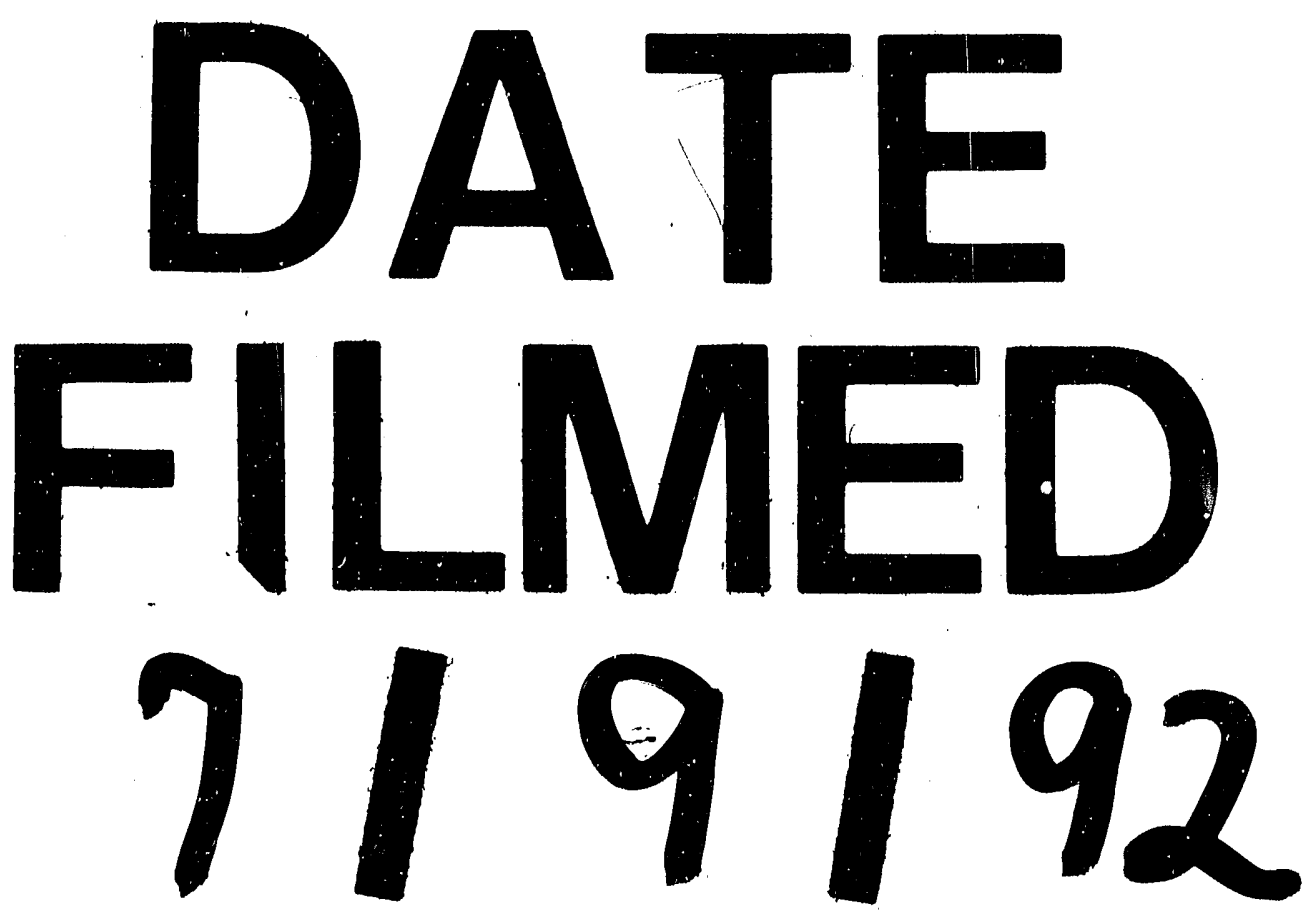
